\title{
A Case of Complete Unroofed Coronary Sinus Syndrome Combined With Coronary Sinus Stenosis Leading to Asymptomatic Presentation
}

\author{
Hye Rin Kim, ${ }^{1}$ Seung Min Yoo, ${ }^{1,}$ Hwa Yeon Lee, ${ }^{2}$ Ji Young Rho, Woo In Yang, Jae Youn Moon, ${ }^{3}$ \\ and Charles S White ${ }^{4}$ \\ ${ }^{1}$ Department of Diagnostic Radiology, CHA University, College of Medicine, Bundang, South Korea \\ Department of Diagnostic Radiology, CHA
${ }^{2}$ Smile Radiologic Clinic, Seoul, South Korea \\ 3 Department of Diagnostic Cardiology, CHA University, College of Medicine, Bundang, South Korea \\ ${ }^{4}$ Department of Diagnostic Radiology, University of Maryland Medical Center, Baltimore, USA \\ ${ }^{*}$ Corresponding author: Seung Min Yoo, Department of Diagnostic Radiology, CHA University, College of Medicine, Bundang, South Korea. Tel:+82-1093300718, E-mail: smyoo68@hanmail.net
}

Received: November 9, 2013; Revised: December 4, 2013; Accepted: December 15, 2013

We describe a patient with an asymptomatic complete unroofed coronary sinus (CS) syndrome associated with the CS stenosis in the absence of a persistent left superior vena cava (SVC) as identified on coronary computed tomography angiography. There was a large defect between the CS and the left atrium (i.e. a large left-to-right shunt), but an unusual combination of the absence of a persistent left SVC (i.e. no risk for brain abscess due to the absence of a right-to-left shunt) and the CS stenosis (i.e. a markedly reduced degree of a left-toright shunt), resulting in an asymptomatic presentation.

Keywords: Coronary Sinus; Stenosis; Multidetector Computed Tomography

\section{Introduction}

The unroofed coronary sinus (CS) syndrome is a rare entity (1-5). Approximately, $75 \%$ of cases with the unroofed CS syndrome are associated with a persistent left superior vena cava (SVC) (1). There is no reported case of an unroofed CS syndrome accompanied by the CS stenosis in the English literature. The clinical presentation of the unroofed CS is generally determined by the size of the defect between the CS and the left atrium (i.e. the degree of a left-to-right shunt) and associated abnormalities (2). We present a case of the complete unroofed CS syndrome with rare associated abnormalities (i.e. the CS stenosis and a collateral pathway through the small cardiac vein and Thebesian vein, but the absence of a persistent left SVC) incidentally identified on coronary computed tomography (CT) angiography. We also propose an explanation of the asymptomatic presentation in this case in spite of the large defect between the CS and the left atrium.

\section{Case Presentation}

A 43-year-old male presented with intermittent atypical chest pain of one month's duration. The patient was otherwise healthy and had no previous medical history. Coronary CT angiography from the tracheal bifurcation to the base of the heart (Lightspeed VCT, GE Healthcare, Milwaukee, WI, USA) to evaluate the underlying cause of the chest pain demonstrated normal coronary arteries. However, a large defect (approximately $2.8 \mathrm{~cm}$ in diameter) between the CS and the left atrium and stenosis of the CS orifice were identified (Figure $1 \mathrm{~A}$ and 1B). The collateral flow from the CS to the right atrium through the small cardiac vein and Thebesian vein was noted (Figure $1 \mathrm{C}, 1 \mathrm{D}$, and $1 \mathrm{E})$. There was no evidence of the enlargement of any cardiac chamber, and nor was there a persistent left SVC identified (Figure $1 \mathrm{~A}$ and $1 \mathrm{~B}$ ). No abnormality was identified at transthoracic echocardiography, although the CT reading was available to the cardiologist performing echocardiography. Transesophageal echocardiography was not performed because the patient was asymptomatic except for the chest pain. A diagnosis of the unroofed CS syndrome with the CS stenosis in the absence of a persistent left SVC was made. The patient was discharged without therapy, and outpatient follow-up was recommended.

Copyright (C) 2015, Tehran University of Medical Sciences and Iranian Society of Radiology. This is an open-access article distributed under the terms of the Creative Commons Attribution-NonCommercial 4.0 International License (http://creativecommons.org/licenses/by-nc/4.0/) which permits copy and redistribute the material just in noncommercial usages, provided the original work is properly cited. 
Kim HR et al.
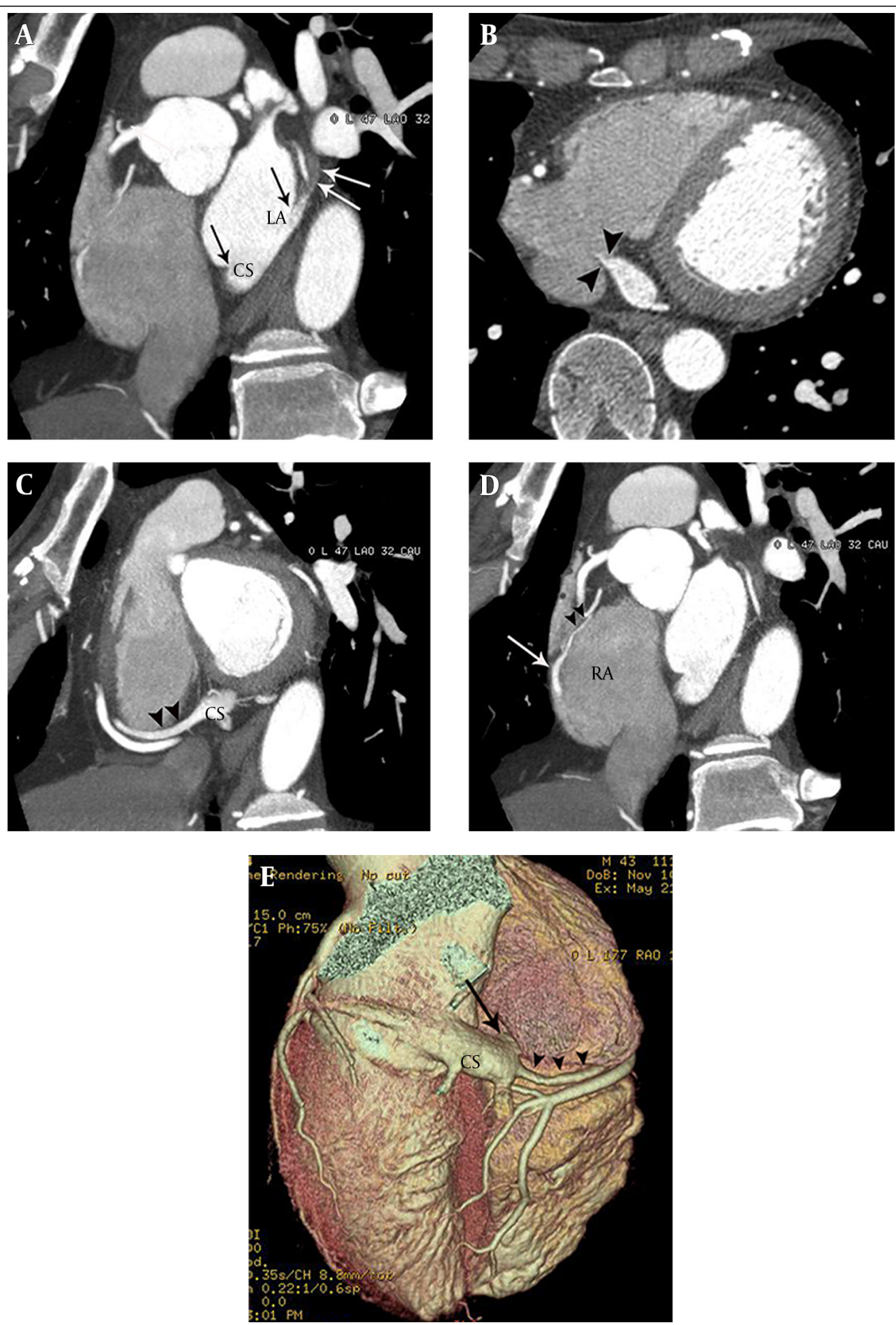

Figure 1. A 43-year-old male with intermittent atypical chest pain undrgoing Coronary CT angiography. A, Note the large defect and similar degree of contrast enhancement in the coronary sinus and left atrium (i.e. complete unroofed coronary sinus) (demarcated between the black arrows) in a short axial multi-planar reformatted computed tomography image. The proximal portion of the coronary sinus (white arrows) is unopacified. There is no evidence of a persistent left superior vena cava draining into the coronary sinus. B, Coronary sinus stenosis (arrowheads) is demonstrated at the orifice draining into the right atrium on a transaxial CT image. There is no cardiac chamber enlargement. C, A collateral pathway from the coronary sinus to the right atrium through the small cardiac vein (arrowheads) is shown on a short axial multi-planar reformatted CT image. D, Note the small Thebesian vein (arrowheads) directly draining into the right atrium and its connection to the small cardiac vein (white arrow) from the coronary sinus. E, Coronary sinus stenosis (arrow) at the orifice draining into the right atrium and a collateral pathway from the coronary sinus to the right atrium through the small cardiac vein (arrowheads) are intuitively demonstrated on a volume-rendered (VR) image (LA, Left atrium; CS, Coronary sinus; RA, Right atrium). 


\section{Discussion}

The unroofed CS syndrome is a rare congenital anomaly that is often associated with a persistent left SVC (1-5). The classification of the unroofed CS syndrome varies in the literature (1-5). It can be classified simply complete or partial depending on the size of the defect between the CS and the left atrium. No previous report exists of a complete unroofed CS syndrome and absence of a persistent left SVC in combination with the CS stenosis leading to a collateral pathway through the small cardiac vein and Thebesian vein identified on coronary CT angiography. This unusual combination of three congenital anomalies remained asymptomatic into adulthood, when the patient presented for unrelated reasons.

The clinical presentation of the unroofed CS syndrome varies from the absence of symptoms to severe right heart failure, and is mainly determined by the size of the CS defect between the CS and the left atrium (i.e. the degree of left-to-right shunting) and associated anomalies such as a persistent left SVC (i.e. brain abscess or infarction caused by a right-to-left shunt) (1-5). The present case had no related symptoms in spite of a large defect between the CS and the left atrium. This was presumably due to the associated CS stenosis and the restriction of the flow by the formation of a collateral flow through the small cardiac and Thebesian veins between the CS and the right atrium. Brain abscess or infarction may be a complication in patients with the unroofed CS syndrome due to paradoxical embolism caused by a right-to-left shunt (1). As there was no associated persistent left SVC, the possibility of a right-to-left shunt was eliminated. Although the underlying cause of chest pain in the present case was not delineated clearly, the chest pain did not seem to be directly related to the unroofed CS syndrome as it had developed recently without accompanying symptoms.

In this instance, multiple detector computed tomography (MDCT) with its high spatial resolution provided not only precise anatomic detail of the unroofed CS syndrome and the associated anomalies, but also a possible explanation for the patient's clinical presentation.

In conclusion, the presence of the CS stenosis and the absence of a persistent left SVC in a patient with an unroofed CS syndrome may result in an asymptomatic presentation, even in the setting of a large CS defect.

\section{Authors' Contributions}

Study concept and design: Seung Min Yoo; Analysis and interpretation of data: This is a case report; Drafting of the manuscript: Hye Rin Kim, Seung Min Yoo, Hwa Yeon Lee, Ji Young Rho, Woo In Yang, Jae Youn Moon, and Charles S White; Critical revision of the manuscript for important intellectual content: Hye Rin Kim, Seung Min Yoo, Hwa Yeon Lee, Ji Young Rho, Woo In Yang, Jae Youn Moon, and Charles S White.

\section{References}

1. Kim H, Choe YH, Park SW, Jun TG, Kang IS, Yang JH, et al. Partially unroofed coronary sinus: MDCT and MRI findings. AJR Am J Roentgenol. 2010;195(5):W331-6.

2. Thangaroopan M, Truong QA, Kalra MK, Yared K, Abbara S. Images in cardiovascular medicine. Rare case of an unroofed coronary sinus: diagnosis by multidetector computed tomography. Circulation. 2009;119(16):e518-20.

3. Brancaccio G, Miraldi F, Ventriglia F, Michielon G, Di Donato RM, De Santis M. Multidetector-row helical computed tomography imaging of unroofed coronary sinus. Int J Cardiol. 2003;91(2-3):251-3.

4. Ootaki Y, Yamaguchi M, Yoshimura N, Oka S, Yoshida M, Hasegawa T. Unroofed coronary sinus syndrome: diagnosis, classification, and surgical treatment. J Thorac Cardiovasc Surg. 2003;126(5):1655-6.

5. Huang XS. Images in cardiovascular medicine. Partially unroofed coronary sinus. Circulation. 2007;116(15):e373. 